\title{
Las visiones de participación y género como herramientas para el análisis de la múltiple dimensión urbana. Una metodología de acercamiento a la realidad urbana
}

\author{
Daniel NAVAS CARRILLO \\ Máster en Innovación en Arquitectura \\ Universidad de Sevilla \\ navascarrillodaniel@gmail.com
}

Recibido: $14 / 03 / 2015$

Modificado: $17 / 05 / 2015$

Aceptado: 23/05/2015

\section{Resumen}

El presente artículo plantea una reflexión sobre las pautas de intervención en la ciudad actual en un momento de crisis social, económica y medioambiental como el que se está viviendo. Se parte del concepto de "Regeneración Urbana Integrada", para entender el hecho urbano como la articulación de múltiples dimensiones, donde el vector social es un componente fundamental que debe ponerse en valor. Se trata de hacer visible la vida de un lugar para poder intervenir en él, estableciendo una estrategia participativa a partir de las vivencias de los residentes, que como usuarios y usuarias de la ciudad realmente tienen el mayor conocimiento de su idiosincrasia. Entre estas experiencias, se ha observado que muchas de las funciones que han venido desarrollando las mujeres en la ciudad aparecen ocultas en el planeamiento. En cambio, éstas son determinantes en la construcción de un nuevo modelo de gestión que sea capaz de incorporar una visión más amplia sobre cómo se vive dicho lugar.

Palabras clave: regeneración urbana integrada, urbanismo y género, participación ciudadana, barriadas obsoletas.

Title: Participation and Gender Views as Tools to Analyze the Multiple Urban Dimension. A Methodology for Approaching to the Urban Reality

\section{Abstract}

This article promotes a reflection about intervention guidelines in the current city at a time of social, economic and environmental crisis as we are experiencing. It begins from the concept of "Integrated Urban Regeneration", to understand the urban reality as the articulation of multiple dimensions, where the social vector is an essential component to be put in value. It is about making visible the life of a place to intervene in. A participatory strategy must be established from their neighbors' practices, who have the better knowledge of their idiosyncrasies. Among these experiences, it has been observed that a lot of the functions that have been developing historically by women in the city are usually hidden in planning. However, this can be decisive in the construction of a new management 
model that would be able to incorporate a broader view of how this place is lived.

Keywords: urban regeneration, urban planning and gender, citizen participation, obsolete neighborhoods.

\section{Índice}

1. Introducción: El paradigma de la ciudad actual

2. La regeneración urbana integral. Hacía una visión holística de lo urbano

3. La necesidad de una sociabilidad previa como soporte de una intervención urbana participada

4. La perspectiva de género como herramienta para un análisis urbano participado

5. Metodología de acercamiento a la ciudad que vivimos

5.1. Construcción del concepto género a partir de la Ética del Cuidado

5.2. Las funciones desempeñadas en la ciudad

5.3. Los espacios de relación y la seguridad

5.4. Movilidad urbana y accesibilidad

5.5. Itinerario para su análisis y cartografía participada

6. Conclusiones

\section{Introducción: El paradigma de la ciudad actual}

En estos momentos, desde numerosos ámbitos de la sociedad, se está cuestionando el modelo urbano expansionista. Éste, heredero de la política económica de crecimiento continuo de los últimos años, ha propiciado que muchas de las barriadas construidas en la segunda mitad del siglo XX hayan quedado obsoletas a una velocidad casi instantánea.

Esto ha llevado a que, en menos de 50 años, muchas zonas de la ciudad hayan pasado de una posición periférica a ser áreas de centralidad $^{1}$. El problema reside en que han dejado de ser atractivas para inversores, ya que por su condición de ciudad consolidada presentan una menor rentabilidad que los nuevos desarrollos de las periferias.

${ }^{1}$ En cualquier ciudad, si se comparan las imágenes aéreas actuales con las del vuelo americano de 1956, se observa que los barrios que se construyeron en la periferia en aquellos años han quedado absorbidos en una trama urbana que ha duplicado o triplicado su superficie. 


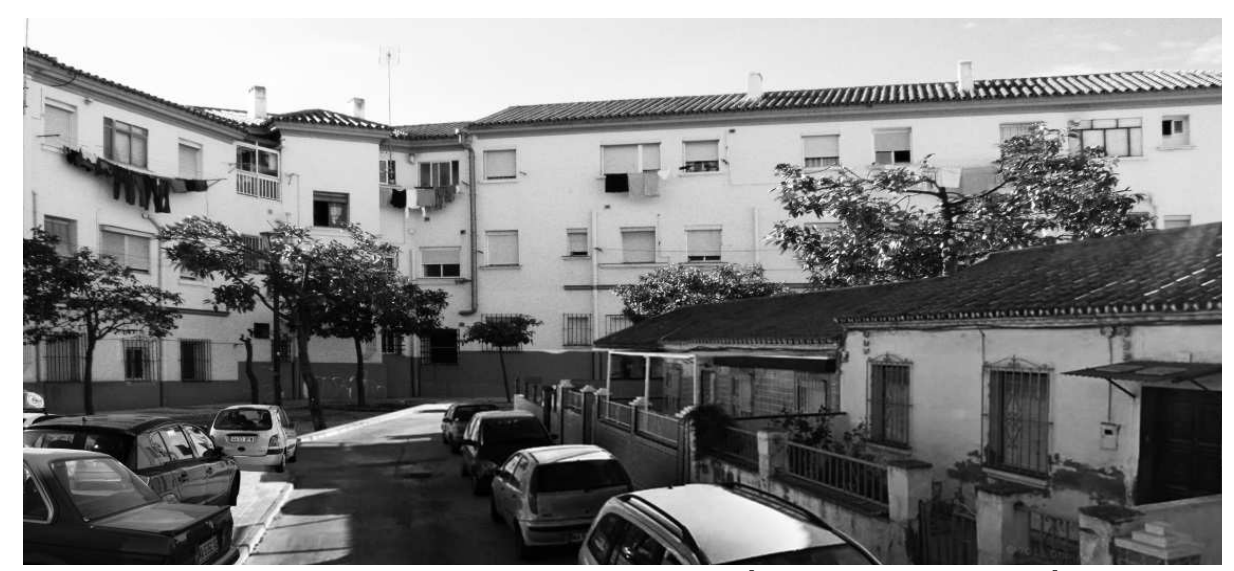

Figura 1. Barriada de Carranque en Málaga. Elaboración Propia.

Nos encontramos ante unas áreas que han quedado totalmente desfasadas, presentando una imagen degradada propia de otra época, y que por tanto genera al transeúnte una sensación de desconfianza, propiciando su aislamiento (figura 1). A esto se debe sumar que son barriadas con un amplio sector poblacional acuciado por serios problemas socioeconómicos, al albergar a los grupos más desfavorecidos ${ }^{2}$.

Resulta urgente una reformulación de estas áreas de manera más acorde con los nuevos condicionantes urbanos, propios de la ciudad del siglo XXI. Estamos ante actuaciones que deben trascender el ámbito exclusivo de lo matérico:

Se distinguen cuestiones arquitectónicas (desencaje tipológico, deficiencias técnicas, deterioro físico), urbanísticas (aislamiento, carencias funcionales, degradación del espacio público) y sociales (desempleo, segregación, conflictividad). (García Vázquez 2013: 5)

Se debe ahondar en aquellos rasgos socioespaciales que sostienen la vida en sociedad, y buscar la hibridación de lo nuevo con aquello que es propio de ese lugar, aquello que subyace a sus propias lógicas, como consecuencia de su devenir autónomo a lo largo de su vida. De no ser así, estaremos ante procesos que llevan consigo que aquellos grupos sociales que difieren del modelo impuesto de vida social moderna, abandonen su lugar habitual de residencia.

El concepto de gentrificación ha servido desde hace 40 años para designar este nuevo proceso de recomposición y sustitución social que se ha producido en el espacio urbano, un proceso estrechamente relacionado con acciones de rehabilitación urbana del parque de viviendas. (Mendes 2009: 760-761)

\footnotetext{
${ }^{2}$ Hay que tener en cuenta que el alto grado de obsolescencia propicia que el precio medio de venta o alquiler de inmuebles sea muy inferior a la oferta residencial en el resto de la ciudad.
} 
Esto hace pensar que las intervenciones sobre la ciudad consolidada, al igual que el desarrollo expansionista, también derivan de las políticas neoliberales que se han estado aplicando sobre el urbanismo, al ser vistas exclusivamente desde términos económicos. El paradigma actual pasa por superar esta barrera y empezar a ver estas barriadas como áreas de oportunidad en la evolución hacia un modelo de ciudad sostenible.

Las áreas urbanas desfavorecidas no deben ser vistas como un problema, sino como fuente de capital urbano y físico desaprovechado y cuyo potencial tiene que ser desbloqueado para que pueda contribuir al progreso cívico y al desarrollo económico general de la ciudad [...]. (Consejo de la Unión Europea 2010: 7-8)

\section{La regeneración urbana integral. Hacía una visión holística de lo urbano}

En el Marco Europeo en materia de Urbanismo, recogido en el Documento de Referencia de Toledo para un desarrollo urbano más inteligente, sostenible y socialmente inclusivo en Europa, se define el concepto de "Regeneración Urbana Integrada", el cual desarrolla la visión dada anteriormente sobre las necesidades de la ciudad actual y el problema sobre cómo actuar sobre ella. Introduce conceptos relativos al pensamiento holístico, esto es, pensar y trabajar en las múltiples dimensiones al mismo tiempo, ya que "[...] pretende optimizar, preservar o revalorizar todo el capital urbano existente (social, urbanístico, patrimonio edificado, etc.)" (Consejo de la Unión Europea 2010: 7).

Se debe atender a una regeneración "verde, ecológica o ambiental", teniendo en la eficiencia energética y las energías renovables un amplio campo de actuación. Se debe incrementar el empleo y la inversión en $\mathrm{I}+\mathrm{D}+\mathrm{i}$, a través de una economía basada en el conocimiento, que además pueda hallar en la rehabilitación residencial posibilidades de diversificación del castigado sector de la construcción. Se exige de una buena gobernanza para la optimización de recursos y esfuerzos mediante la cooperación y las sinergias de una gobernanza multinivel, que fomente el empoderamiento ciudadano. Es necesario conservar sus edificios históricos, la puesta en valor del espacio público y la creación o recreación de los valores urbanos, al introducir el concepto de Baukultur. "Este concepto [...] ha de entenderse en el sentido más amplio de la palabra, como la suma de todos los aspectos culturales, económicos, tecnológicos, sociales y ecológicos que influyen en la calidad y en el proceso de planificación y construcción" (Consejo Informal de Ministros de Urbanismo de la Unión Europea 2007: 4). 
A todo ello se suma que la ciudad es tiempo y espacio. Esto nos lleva a pensar en la construcción de "escenarios estratégicos" que permitan fijar unas líneas generales de actuación a medio o largo plazo. Éstas serán lo suficientemente flexibles como para que se adapten a los condicionantes particulares de cada fase, y estarán marcadas por el propio devenir urbano.

Analizando los casos de estudio recogidos por Velázquez Valoria y Vedarguer Viana-Cárdenas en su texto Regeneración urbana integral Tres experiencias europeas innovadoras, se extrae que la estrategia debe pasar por fijar una estructura de totalidad, donde se integren acciones concretas, pero dentro de los objetivos generales establecidos. Se trata de un proceso de feedback o correlación entre la escala macro o global, y la micro o territorializada (area based). De su articulación dependerá el éxito o fracaso de cualquier intervención sobre la ciudad preexistente.

Es importante mencionar que este concepto también hace referencia a lo que debe ser un proceso integrador. Por una parte, la ciudad posibilita la construcción social, y, al mismo tiempo, la articulación social posibilita que realmente se construya ciudad. En este sentido, es primordial generar estructuras que combatan las desigualdades sociales, a la vez que se construyen procesos participativos que sean capaces de integrar la multiplicidad social que impera en las ciudades, sin excluir de ellos a ninguna persona por razones socioeconómicas, culturales e incluso atendiendo a su capacitación técnica.

Mediante la llamada gobernanza multinivel, se articulan sinergias de abajo hacia arriba como respuesta al tradicional flujo de arriba hacia abajo. Esto implica la participación de un amplio espectro poblacional, asumiendo el empoderamiento de la ciudadanía. Como máxima, el personal técnico y la clase política que se enfrentan al hecho urbano deberían asumir que la satisfacción y el bienestar de la ciudadanía son claves para que cualquier intervención llegue a buen puerto.

\section{La necesidad de una sociabilidad previa como soporte de una intervención urbana participada}

Para poder evaluar las necesidades existentes, es fundamental elaborar un proyecto previo que establezca las bases para una estrategia participativa de regeneración urbana. Ésta debe partir de las experiencias de quienes residen en la zona, que al hacer uso de la misma son los verdaderos conocedores de sus necesidades y potencialidades. El objetivo buscado es el de crear una sociabilidad previa que dé soporte a la intervención y pueda asumir el espacio como propio.

Si la población se implica de forma directa en la búsqueda consensuada de una solución urbana, se sentirá parte indispensable 
de la misma. Al tomar conciencia sobre el proceso llevado a cabo, se asegurará el cuidado y mantenimiento de la solución resultante. Es necesario asumir que "la ausencia de espacios que el ciudadano sienta como suyo, bien de forma individual o de manera colectiva, motiva el vandalismo y la agresividad" (Panerai y Mangin 2002: 7).

El hecho de dejar a cada usuario total libertad para que aporte sus reivindicaciones sobre el lugar dará lugar a conflictos. Massimo Cacciari nos da pistas sobre cuáles han de ser las características de la comunidad para el éxito de esta sociabilidad previa:

Para que haya comunidad es necesario, pues, que ésta se constituya entre seres auténticamente distintos, entre el extranjero, el peregrino, que trae consigo sus propias leyes y sus costumbres propias, y el que le acoge y a su vez se reconoce siempre intrínseca y potencialmente como hostis. El cum no tendría razón de subsistir entre idénticos [...]. En este caso no hay comunidad, sino mera cohabitación. (Cacciari 1997: 58-59)

Se comprueba que es necesaria la confrontación, un parlamento en el cual sus usuarios se reconozcan como elementos distintos pero con un objetivo conjunto: el de convivir. Sólo en la distancia se genera la comunidad, y sólo la comunidad es portadora de la verdad. Por ello, a la hora de decidir sobre cuáles son las intervenciones a realizar, no importa la decisión final, sino el proceso de debatir qué es mejor. Si el lugar propio de una comunidad tiene sentido si se ha gestado de forma colectiva, ¿qué sentido tiene una ciudad no participada?

Siguiendo esta idea, las experiencias de regeneración urbana participada que está desarrollando Paisaje Transversal demuestran que éstas deben surgir en colaboración con el movimiento asociativo del lugar. Éstos, al tener un papel activo y estar en contacto directo con un amplio espectro social, pueden ser los abanderados de la labor de concienciación necesaria para que un mayor número de usuarios participen sobre las necesidades urbanas.
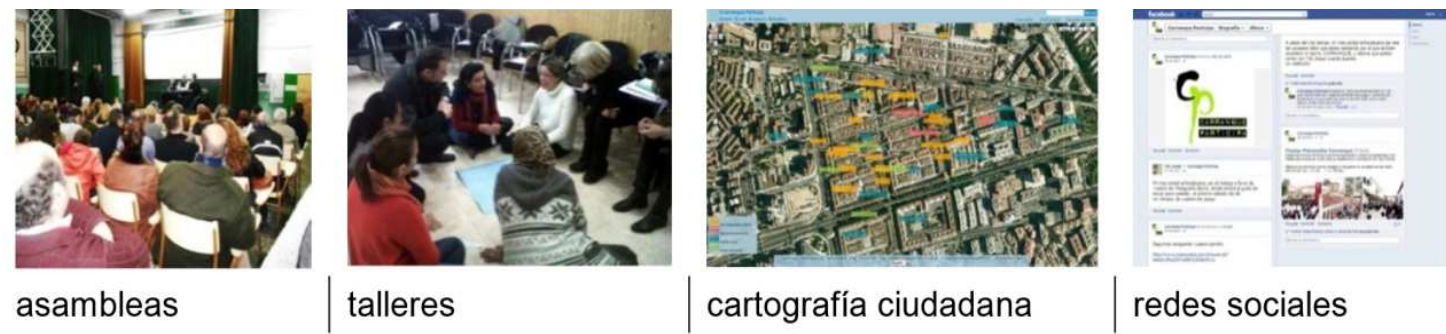

Figura 2. Herramientas de participación. Iniciativa Carranque Participa.

Para ello, las herramientas 2.0 han supuesto un revulsivo a las actividades que venían tradicionalmente realizando las asociaciones de vecinos. Así, además de talleres y asambleas vecinales, el uso de 
las redes sociales y las herramientas online de cartografía ciudadana permiten a la población residente formar parte del proyecto de forma sencilla y cómoda, colaborando desde casa y sin ocuparles demasiado tiempo (figura 2).

\section{La perspectiva de género como herramienta para un análisis urbano participado}

Ya desde los años 70 se viene reivindicando la incorporación de aspectos sociológicos en el diseño urbano. Muerte y vida de las grandes ciudades, escrito por la activista urbana Jane Jacobs, es reconocido como uno de los primeros manifiestos en defensa de una visión más inclusiva en el planeamiento. En su afán por sistematizar las intervenciones urbanas, el planeamiento se ha basado en parámetros cuantitativos ${ }^{3}$, dejando de lado cuestionamientos relacionados con la vida de la ciudad, cuestión clave para la felicidad y el bienestar de toda la población.

Es aquí donde puede entrar la perspectiva de género. Al tener como objeto de estudio un grupo poblacional más amplio, se convierte en instrumento para articular verdaderos procesos participativos. La cuestión reside en que las mujeres, estadística e históricamente, han venido desarrollando una serie de funciones que las posicionan como catalizadoras de minorías sociales que han pasado totalmente desapercibidas en el diseño de la ciudad contemporánea. Aunque las labores relacionadas con la reproducción y el cuidado del hogar se estén gestionando actualmente de forma conjunta, "son mayoritariamente las mujeres las que siguen ocupándose del cuidado de los grupos más vulnerables de la sociedad: niños, personas mayores, adultos y personas con movilidad reducida" (García Bujalance y Royo Naranjo 2012).

En este sentido, la perspectiva de género en el urbanismo no debe entenderse únicamente desde la reivindicación de la visibilización femenina, que también, sino como el modo en que el personal técnico y el resto de agentes que intervienen en los procesos de toma de decisiones sobre las ciudades pueden tener para llegar a un espectro más amplio de las necesidades ciudadanas.

Esta nueva concepción de la manera de enfrentarse al hecho urbano ha tenido un desarrollo reflexivo extenso por parte de investigadoras del ámbito universitario español. Ha sido

${ }^{3}$ El planeamiento urbanístico actual está encorsetado al responder a una serie de parámetros numéricos de índole general que difícilmente son capaces de adaptarse al devenir de la ciudad a lo largo de su vigencia. Por ejemplo, mediante la ratio de equipamientos, se pretende suplir las necesidades urbanas en el momento de redacción del plan, pero puede que cuando realmente se vayan a construir las necesidades hayan cambiado y donde se había proyectado una escuela infantil, sea necesaria una residencia para mayores. 
especialmente significativo a raíz de la constitución del primer grupo de investigación sobre género y urbanismo, "Generourban", fundado por Anne Alix Le Maignan e Inés Sánchez de Madariaga en la Universidad Politécnica de Madrid en el año 2000. En años posteriores, se han formado otros grupos de relevancia como el que dirige Zaida Muxí en la Universidad Politécnica de Barcelona, o el "Aula Eileen Gray" del Colegio de Arquitectos de Córdoba.

"Tras este esfuerzo de investigación y concienciación se empieza ahora a avanzar sobre el siguiente paso: la innovación en las políticas públicas y en las prácticas profesionales" (Sánchez de Madariaga 2012: 10-11). Éstas tienen un hito en las leyes de Igualdad y del Suelo, ambas aprobadas en 2007, consecuencia directa del Tratado de Ámsterdam de la Unión Europea. Mediante este marco común, aprobado en 1997, se ha empezado a introducir la cuestión de género de forma transversal en las políticas públicas de los estados miembros.

En este contexto, nos encontramos ante la necesidad de repensar la ciudad construida con el objetivo de definir una arquitectura, un urbanismo y un territorio inclusivos, que atiendan a la diversidad de la sociedad actual, contemplando sus diferencias sociales, culturales, etc., y adaptándose a las necesidades propias de cada género.

\section{Metodología de acercamiento a la ciudad que vivimos}

En los últimos años han proliferado diversas experiencias basadas en el entendimiento de la cuestión de género como una herramienta útil en cualquier análisis participado sobre la ciudad consolidada.

Algunas de las primeras experiencias en el análisis urbano desde una perspectiva de género han venido de la mano del "Colectivo punto 6, mujeres constructoras de ciudad". En 2006, este colectivo empezó a desarrollar talleres de aplicación de la visión de género en la revisión del espacio público en distintos barrios de la ciudad de Barcelona. Sus últimos trabajos de diagnosis sobre participación y género se han centrado en generar una base sobre la que construir nuevos proyectos urbanos. A partir de estas experiencias, han desarrollado diversos protocolos de análisis que engloban bajo el título de "Auditoría de género urbana".

La introducción de cuestiones de género en la redacción del planeamiento urbanístico ha sido regulada por las distintas comunidades autónomas, propiciando interesantes ejemplos. La iniciativa "albaceteplural", desarrollada entre 2009 y 2010, ha sido una las precursoras en este sentido. Da un paso adelante al definir la participación ciudadana como la acción básica para incorporar la perspectiva de género en el Plan General de Ordenación Urbana de Albacete. 
A partir de éstas, se pueden mencionar otras experiencias que han venido a profundizar en la necesidad de trasladar a la ciudadanía, y en especial a las mujeres, la importancia de conocer la relación recíproca entre los efectos que genera la ciudad en ellas, y la construcción que éstas realizan de la ciudad.

El seminario desarrollado en Vitoria en 2011 bajo el título de "Urbanismo Inclusivo. La calle tiene género" (Mujika Munduate 2012), - los talleres de "Ciudad y Género" organizados por el Área de Igualdad del Ayuntamiento de Málaga (García Bujalance 2013), son ejemplos en los que se ha tomado como objeto la construcción de una nueva conciencia crítica sobre los problemas de la ciudad, necesaria para poder debatir sobre ella.

\subsection{Construcción del concepto género a partir de la Ética del Cuidado}

Previamente a cualquier análisis participado que se base en cuestiones de género, es necesario establecer una propuesta de aprendizaje personal basada en un proceso constante de construcción y deconstrucción del concepto de género. Al mismo tiempo es preciso escenificar la diferencia entre la Ética de la Justicia y la Ética del Cuidado, y su vínculo con la esfera de lo femenino.

Según la teoría queer de Judith Butler, la identidad sexual es una elaboración narrativa propia que debe estar abierta a otras identidades para no convertirse en una verdad acabada y limitada. Se debe entender que la construcción de la identidad debe ir unida a la confrontación de la alteridad y de lo diferente, para ser liberadora y emancipadora:

\footnotetext{
Se trataría de acabar con la identidad mujer y abrir el espacio a nuevas construcciones de la identidad en las que tanto los géneros como los sexos inteligibles, esos sexos que cuentan en el discurso social, proliferen y, alejándose del planteamiento dualista, se hagan múltiples. (Expósito García 2010: 106)
}

Se propone así la necesidad de contactar con otras sensibilidades y posiciones respecto al género como construcción participada de la sexualidad, y contrastarlos con los que cada individuo tiene preconcebidos. Este proceso propicia un mecanismo para la construcción colectiva de un nuevo concepto, en este caso el de género, pero a la vez favorece la elaboración de una identidad propia que tiene cabida en una colectividad $y$, por tanto, motivando un sentimiento de pertenencia a ella.

Para esta construcción colectiva es importante aclarar las diferencias fundamentales entre dos modelos éticos que vienen a confrontar dos bases muy diferentes. Es importante señalar que la identificación de estas dos visiones desarrolladas en la teoría moral 
de Carol Gillian, "está[n] lejos de querer sustituir una perspectiva por la otra y que la relación es concebida en términos de perspectivas éticas complementarias" (Fascioli 2010: 42).

Por un lado, la Ética de la Justicia surge en el siglo XVIII ligada a la lucha ideológica de una burguesía ascendente interesada en suprimir los derechos originados por el nacimiento. Así, se basa en la concepción del individuo como hombre desarraigado $y$, en consecuencia, sin contexto. De ahí que sea una ética que aplica la segregación entre la esfera pública y la privada, dicotomía hasta entonces inexistente. Su objeto es exclusivamente la resolución de conflictos en el ámbito público mediante el consenso, sin valorar el contenido de los mismos.

Frente a ésta ética, existe otra aplicada a la esfera de lo privado centrada en las necesidades de lo concreto. "La Ética del Cuidado [...] se preocupa por la actividad de dar cuidado, centra el desarrollo moral en torno al entendimiento de la responsabilidad y las relaciones" (Gilligan 1985: 42).

Se trata de una ética incluyente, ya que abarcaría dos esferas que hasta ahora habían permanecido separadas: la de las acciones públicas y la de los efectos en la vida. Por tanto, se pone en crisis esta dicotomía, ya que la sociedad, y especialmente las mujeres, se valen de las capacidades desarrolladas en el ámbito privado para resolver problemas de la esfera pública.

\subsection{Las funciones desempeñadas en la ciudad}

Una vez fijado el marco conceptual para su aplicación al ámbito urbano, se pueden identificar las distintas funciones que tradicionalmente han desempeñado las mujeres en la ciudad, aunque también haya hombres que las realicen. La importancia de mirar la ciudad a través de los ojos de las mujeres reside en poder aproximarse al diseño urbano atendiendo a un rango muy amplio de exigencias y necesidades de la ciudadanía. De este modo se consigue abandonar la concepción generalizada en el diseño pensado para un ciudadano caracterizado como hombre independiente, sin cargas y que preferiblemente se mueve por la ciudad en vehículo propio. 


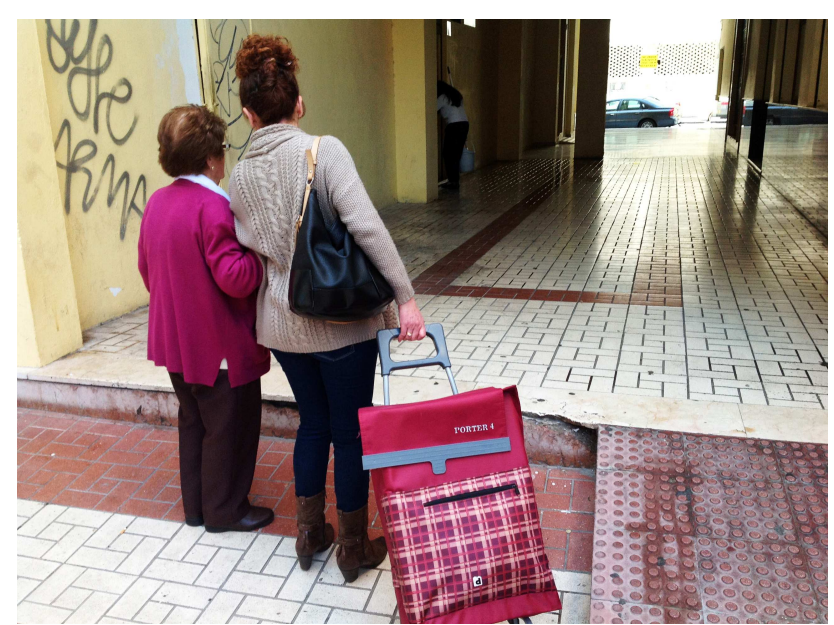

Figura 3. Funciones de la mujer en la ciudad. Elaboración Propia.

Mediante los comentarios y apreciaciones sobre una serie de imágenes, es posible explicitar las funciones que las mujeres pueden identificar como propias y cuáles, de un modo inconsciente, les son atribuidas por el resto de ciudadanos, e incluso por ellas mismas (figura 3). En este sentido, es importante mostrar la importancia de la observación del mundo en que se habita con el propósito de identificarse y ubicarse en él. El objetivo consiste en ser consciente del importante papel que desempeña la mujer como ciudadana, más allá del que se les presupone. Identificando y reconociendo las funciones ocultas que las mujeres desempeñan dentro de la sociedad, se capacitan para la exigencia y apropiación de un espacio público acorde a sus necesidades.

A partir de las funciones asumidas, se precisa profundizar sobre la idea de imagen: tanto la que las mujeres muestran en la ciudad, como la que la ciudad proyecta de ellas. Cualquier ciudad, como escenario donde todo individuo se relaciona, arroja una determinada imagen de cada cual, de la que no se es consciente la mayoría de los veces.

Independientemente del sexo de cada persona, existe una exigencia general en el ámbito público que asocia la imagen con un perfil tipo, desechando otras imágenes de nosotros mismos que también nos definen. Es importante concienciar sobre las consecuencias que tienen ciertos estereotipos exigidos, a la hora de conciliar las actividades que se tienen que realizar a lo largo del día.

Para cada actividad diferenciada que realizamos, estamos asumiendo una determinada función representativa, a través de la cual el resto de individuos nos van a reconocer dentro de un determinado papel. Con ello se reconoce que cada función desarrollada en nuestra vida cotidiana influye en mayor o menor medida en la imagen que los demás van a tener de nosotros y en la imagen que nosotros mismos identificamos como propia. 


\subsection{Los espacios de relación y la seguridad}

La mujer ha asumido históricamente un papel fundamental en la creación de los tejidos sociales y las relaciones de solidaridad vecinal, así como en la gestión de los conflictos urbanos.

Este papel de facilitadoras de la vida cotidiana [...] se concentra en el espacio en un uso considerablemente más intenso de los equipamientos, de los servicios que la ciudad pone a disposición de los ciudadanos. (Román y Velázquez 2008: 49-50)

Estas funciones demandan repensar cómo deben ser estos espacios específicos de relación y convivencia. Tal como afirma Nora Rabotnikof en su ensayo En busca de un lugar común. El espacio público en la teoría política contemporánea, sólo si se tienen en cuenta los "procesos socioespaciales" en el espacio público se articulará lo común, lo visible y lo abierto que viene a sustentar la base de cualquier colectivo.

Pero en el espacio público no sólo se producen la convivencia y el encuentro con el otro. Las calles y parques se convierten en ocasiones en escenarios urbanos donde la mujer siente miedo (figura 4). La inseguridad no necesariamente tiene que ser real. "La percepción de inseguridad en general hace referencia a percepciones y emociones subjetivas de la ciudadanía, y por tanto, no siempre se corresponde con índices objetivos de seguridad y delito" (San Juan 2012: 33).

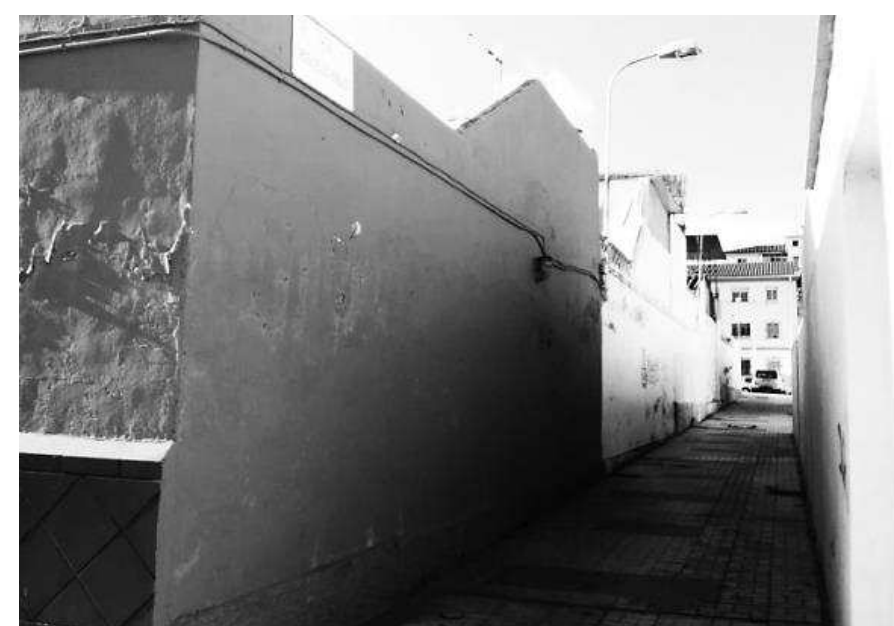

Figura 4. Inseguridad Percibida. Barriada de Carranque en Málaga.

En muchos casos, es sólo la percepción de la misma la que obliga a muchas mujeres a no desplazarse libremente por el espacio público. "La percepción de seguridad en el espacio público es condición indispensable para garantizar la igualdad de acceso a éste para toda la ciudadanía" (Hiria Kolektiboa 2010: 20). En este sentido, el hacer que las mujeres se sientan seguras en la ciudad lleva 
asociado que un mayor número de grupos poblacionales se sientan seguros.

\subsection{Movilidad urbana y accesibilidad}

Posiblemente, una de las mayores formas de discriminación que la ciudad genera hoy en día tiene que ver con la limitación de la movilidad de determinados colectivos. La relación que existe entre los tejidos urbanos y los desplazamientos que se realizan a lo largo y ancho de la ciudad hace que los flujos de movilidad sean determinantes para comprender de qué manera éstos condicionan el acceso libre para muchas personas.

Según Imanol Ilárraz en su texto "Movilidad sostenible y equidad", las pautas de movilidad de mujeres y hombres son diferentes, agrupando en tres bloques las principales razones que justifican este hecho: "aspectos relacionados con la posición socioeconómica de las mujeres, aspectos relacionados con la gestión del territorio y aspectos relacionados con la seguridad" (Ilárraz Rodríguez 2006: 338-339).

En cuanto a la primera, cuando sólo se dispone de un coche en la unidad familiar, existe un menor acceso de las mujeres al uso del mismo, tal como señala la siguiente afirmación fruto de diversos estudios sobre pautas de movilidad en la ciudad de Londres:

El patrón general era que los maridos tenían la primera opción para usar el coche, normalmente para ir a trabajar, y las esposas debían depender del transporte público, o esperar que las llevaran para satisfacer sus necesidades de desplazamiento. (Hamilton, Hoyle y Jenkins 2000: 17)

En relación a la segunda, la condición de los desplazamientos que se realizan viene a responder a las funciones que le son propias a cada género. Mientras que las mujeres desarrollan habitualmente recorridos poligonales (de casa al colegio, del colegio al trabajo, del trabajo a la tienda...), el desplazamiento propio de los hombres es de tipo pendular (de casa al trabajo). Esto hace que observar sus necesidades en la movilidad sea un mecanismo de aproximación muy útil para tratar de identificar y comprender los flujos urbanos.

Por último, la proliferación de barrios residenciales de baja densidad fomenta el aislamiento de muchas mujeres. Tengamos en cuenta que no sólo son usuarias de estos barrios quienes residen allí, sino quienes trabajan en actividades domésticas y de cuidado de niños y ancianos. Al contar con una baja densidad, las autoridades no las dotan del transporte público necesario ni en recorridos ni en frecuencia, aumentando la sensación de inseguridad percibida. 


\subsection{Itinerario para su análisis y cartografía participada}

Una vez que han sido fijados los conceptos necesarios para asumir una visión crítica sobre el hecho urbano, se puede testar lo aprendido sobre el ámbito donde se desarrollen la amplia mayoría de actividades cotidianas.

La propia decisión sobre qué recorrido realizar debe ser la primera cuestión consensuada. No sólo se deben englobar aquellos lugares que tengan algún tipo de interés para una mayoría, sino que también deben tenerse en cuenta aquellos espacios de relevancia personal para cada cual. Esta primera fase requiere de un esfuerzo de concienciación individual para reconocer la vinculación con el lugar que se habita, y poder así hacer partícipe a los demás de las propias vivencias.

Es importante destacar que esta fase es fundamental para el aprovechamiento de la experiencia, pues con la invitación a la reflexión sobre la importancia del hecho urbano, se muestra cómo se condiciona el desarrollo del día a día. De este modo se sientan las bases necesarias en cualquier proceso participativo para articular el debate y la reflexión sobre las prioridades que cada barrio o área de la ciudad tiene, en relación a las propias prioridades de sus vecinos.

Experiencias como los "mapas de la ciudad prohibida" Ilevadas a cabo en distintos municipios del País Vasco (Hiria Kolektiboa 2010), han demostrado que la elaboración de una "cartografía ciudadana" (figura 5) es una herramienta útil para experimentar en el espacio propio una nueva mirada crítica sobre la ciudad.

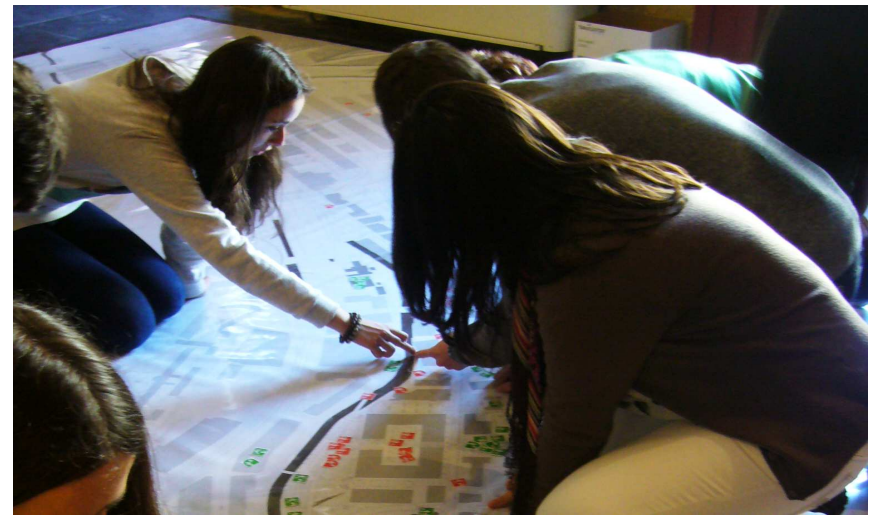

Figura 5. Mapa de la ciudad prohibida. Fuente: Hiria Kolektiboa.

Al ir fotografiando y tomando notas de las impresiones que van surgiendo a medida que se avanzaba por el recorrido propuesto, se detectan numerosos aspectos que no habían sido representados en los planos del planeamiento urbano y que, sin embargo, afectaban de manera determinante en la cotidianeidad. 


\section{Conclusiones}

La regeneración urbana integrada responde a los objetivos que se ha marcado la Unión Europea en la Estrategia 2020 al abordar el hecho de la sostenibilidad desde múltiples acepciones. Este acercamiento pretende poner fin al modelo urbano expansivo, haciendo frente a las consecuencias medioambientales de la dispersión urbana.

Ahora bien, de los modelos de regeneración urbana analizados, se extrae que la clave para el éxito de cualquier actuación en la ciudad consolidada pasa por la construcción de una sociabilidad previa catalizadora de las necesidades de lo colectivo. Aunque existan mecanismos para la participación oficial, ésta sigue siendo una de las asignaturas pendientes. Según se ha analizado, el problema reside en que estos mecanismos carecen de utilidad cuando se utilizan para demandar de manera individual. Es importante recuperar la conciencia de unidad vecinal, de colectivo de afectados por una determinada problemática o de grupos de interés en aspectos específicos como la recuperación del patrimonio, los carriles bici o los grupos ecologistas.

Todos ellos, junto con las instituciones, deben encontrar un punto de encuentro en el que las necesidades y condicionantes de cada uno puedan ensamblarse para crear propuestas de consenso. Pero esto no será posible si no se modifica la percepción que los ciudadanos tienen de su propia ciudad. Es necesaria la capacitación para la lectura e interpretación de los procesos urbanos en el ámbito de lo cotidiano, y no sólo en el de las decisiones globales que suelen resultar ajenas.

Para ello, contar con las mujeres como ciudadanas preferentes en la gestión de la ciudad, por su especial atención a múltiples funciones que normalmente aparecen ocultas para el planeamiento, es una manera útil de experimentar e incorporar una visión más amplia de las necesidades vitales de las personas en la ciudad. 


\section{Bibliografía}

CACCIARI, Massimo (1997): "La invención del individuo", en Carlo Maria Martini y Massimo Cacciari (eds.), Diálogo sobre la solidaridad. Barcelona: Herder.

CONSEJO DE LA UNIÓN EUROPEA (2010): Declaración de Toledo de la Reunión Informal de Ministros de Desarrollo Urbano de la UE. Toledo: Presidencia Española de la UE.

CONSEJO INFORMAL DE MINISTROS DE URBANISMO DE LA UNIÓN EUROPEA (2007): Carta de Leipzig sobre Ciudades Europeas Sostenibles. Leipzig: Presidencia Alemana de la UE.

EXPÓSITO GARCÍA, Mercedes (2010): "El devenir del sistema sexo-género. La necesidad de hablar de las mismas cosas". Cuadernos Kóre, vol. 1, núm. 2.

FASCIOLI, Ana (2010): "Ética del cuidado y ética de la justicia en la teoría moral de Carol Gilligan". Actio, núm. 12.

GARCÍA BUJALANCE, Susana (2013): "Conocemos y Cuidamos nuestros barrios: Taller 'Ciudad y Género'" [en línea]. Laboratorio de Urbanismo, 25/01/2013.

https://laboratoriodeurbanismo.wordpress.com

[Consulta: 28/02/2015].

GARCÍA BUJALANCE, Susana; y ROYO NARANJO, Lourdes (2012): "La perspectiva de género en el urbanismo. Una aproximación conceptual adaptada", en Isabel Vázquez Bermúdez (ed.), Actas del IV Congreso Universitario Nacional "Investigación y Género" (Sevilla, junio 2012). Sevilla: Unidad para la Igualdad de la Universidad de Sevilla.

GARCÍA VÁZQUEZ, Carlos (2013): Manual de Buenas Prácticas: Obsolescencia de Barriadas. Memoria inicial. Sevilla: Consejería de Fomento y Vivienda de la Junta de Andalucía.

GILLIGAN, Carol (1985): La moral y la teoría. Psicología del desarrollo femenino. México: Fondo de Cultura Económica.

HAMILTON, K.; HOYLE, S. R.; y JENKINS, L. (2000): Public Transport Gender Audit Evidence Base. Londres: Department for Transport.

HIRIA KOLEKTIBOA (2010): Manual de análisis urbano. Género y vida cotidiana. Manual metodológico. Vitoria-Gasteiz: Departamento de Vivienda, Obras Públicas y Transporte del Gobierno Vasco.

ILÁRRAZ RODRÍGUEZ, Imanol (2006): "Movilidad sostenible y equidad", en XVI Congreso de Estudios Vascos (Bilbao, 2005), pp. 337-342. Donostia-San Sebastián: Eusko Ikaskuntza.

JACOBS, Jane (1973): Muerte y vida de las grandes ciudades. Madrid: Península.

MENDES, Luís Filipe Gonçalves (2009): "Gentrificación y Rehabilitación Urbana: La ambigüedad y la certeza en la afirmación de la ciudad contemporánea", en 5th International Conference Virtual City and Territory (Barcelona, junio 2009), pp. 759-768. Barcelona: Centre de Política de Sòl i Valoracions.

MUJIKA MUNDUATE, Alazne (2012): Urbanismo Inclusivo. Las calles tienen género. Vitoria-Gasteiz: Servicio Central de Publicaciones del Gobierno Vasco.

PAISAJE TRASVERSAL (2013): "Un plan de barrio para Virgen de Begoña" [en línea]. Paisaje Transversal: reflexión urbana para la imaginación 
colectiva, 23/06/2012. En: http://www.paisajetransversal.com [Consulta: 28/02/2015].

PANERAI, Philippe; y MANGIN, David (2012): Proyectar la Ciudad. Madrid: Celeste.

RABOTNIKOF, Nora (2005): En busca de un lugar común. El espacio público en la teoria política contemporánea. México: Universidad Nacional Autónoma de México.

ROMÁN, Marta; y VELÁZQUEZ, Isabela (2008): "Planificar desde otra óptica", En Marta Román e Isabela Velázquez (eds.), Guía de urbanismo con perspectiva de género, pp. 45-58. Murcia: Ediciones de la Consejería de Política Social, Mujer e Inmigración.

SAN JUAN, César (2012): "Estudio sobre mapas de la criminalidad y percepción de la inseguridad", en Alazne Mujika Munduate (ed.), Urbanismo inclusivo. Las calles tienen género, pp. 33-40. VitoriaGasteiz: Servicio Central de Publicaciones del Gobierno Vasco.

SÁNCHEZ DE MADARIAGA, Inés (2012): "Albaceteplural, una experiencia de modernización", en Mercedes Miranda Bleda, Eva M. Álvarez Isidro y M. Elia Gutiérrez Mozo, Albaceteplural. Incorporación de la perspectiva de género a la redacción del Plan de Ordenación Municipal de Albacete: gestión de la participación, pp. 10-11. Albacete: Ayuntamiento de Albacete.

VELÁZQUEZ VALORIA, Isabela; y VEDARGUER VIANA-CÁRDENAS, Carlos (2011): Regeneración urbana Integral. Tres experiencias europeas innovadoras: Île de Nantes, Coin Street y Barrio La Mina. Madrid: Sepes. 